\title{
MENINGITE: BREVE ANÁLISE SOBRE O PERFIL EPIDEMIOLÓGICO NO BRASIL- BR, NOS ANOS DE 2018 E 2019
}

\author{
${ }^{* 1}$ Adriano Menino de Macedo Junior, ${ }^{2}$ Giancarlo Paiva Nicoletti and ${ }^{2}$ Elizabeth Cristina \\ Gomes dos Santos
}

1Farmacêutico - Generalista. UNICEUNA - Centro Universitário Natalense. Departamento Farmácia. Natal, Rio Grande do Norte, Brasil; ${ }^{2}$ Professor Titular da UNICEUNA - Centro Universitário Natalense. Departamento de Farmácia. Natal, Rio Grande do Norte, Brasil

\section{ARTICLE INFO}

\section{Article History:}

Received $27^{\text {th }}$ October, 2020

Received in revised form

$19^{\text {th }}$ November, 2020

Accepted $26^{\text {th }}$ December, 2020

Published online $30^{\text {th }}$ January, 2021

Key Words:

Saúde Pública, Meningite,

Epidemiologia, Epidemia.

\begin{abstract}
A meningite é uma doença grave, de grande relevância para a saúde pública, responsável por elevada taxa de mortalidade, que atinge o Sistema Nervoso Central, ocasionada por diferentes agentes etiológicos podendo ser de origem infecciosa e não infecciosa. O presente estudo consiste em um estudo transversal, descritivo e retrospectivo, no qual propôs verificar o perfil epidemiológico da meningite no Brasil, no período de 2018 e 2019, evidenciando as variáveis tipo de etiologia, sexo, idade, zona de residência e grau de escolaridade. Os dados foram obtidos no Sistema Nacional de Agravos de Notificação (SINAN), disponibilizados pelo DATASUS. A meningite asséptica foi a mais predominante, com 49,61\% $(\mathrm{n}=16.125)$ dos casos positivos pesquisados; o sexo masculino prevaleceu com 58,20\% $(n=19.277)$, sendo a faixa etária de $20-39$ anos $(19,59 \%, n=6.487)$ a mais acometida pela doença estudada. A zona urbana foi a mais afetada pela meningite correspondendo a $92,15 \%(n=30.521)$. Quanto ao grau de escolaridade, a doença atingiu mais a população com ensino médio completo $(6,8 \%, n=2.252)$, seguido da população de $5^{\mathrm{a}}$ a $8^{\mathrm{a}}$ série incompleta do ensino fundamental $(5,93 \%, n=1.965)$. É importante que a notificação compulsória seja realizada de forma correta, para que não haja a subnotificação dos casos de meningite, contribuindo para que a vigilância epidemiológica possa ter um maior controle nas estatísticas, e dessa forma desenvolver medidas a partir dos valores reais referentes aos casos de meningite, melhorando o manejo clínico do paciente, bem como, as ações de educação em saúde para lidar com a prevenção. Além de melhorar a qualidade de vida da população e reduzir a taxa de letalidade e morbidade.
\end{abstract}

*Corresponding author: Adriano Menino de Macedo Junior

Copyright (C) 2021, Adriano Menino de Macedo Junior et al. This is an open access article distributed under the Creative Commons Attribution License, which permits unrestricted use, distribution, and reproduction in any medium, provided the original work is properly cited.

Citation: Adriano Menino de Macedo Junior, Giancarlo Paiva Nicoletti and Elizabeth Cristina Gomes dos Santos, 2021."Meningite: breve análise sobre o perfil epidemiológico no Brasil-Br, nos anos de 2018 e 2019”' International Journal of Development Research, 11, (01), 43751-43756

\section{INTRODUÇÃO}

A meningite é uma doença ocasionada pela inflamação das meninges que revestem o Sistema Nervoso Central (SNC), que abrange o cérebro e a medula espinhal. As meninges são constituídas por três membranas denominadas dura-máter, aracnoide e pia-máter, sendo que o processo inflamatório ocorre no espaço subaracnóideo, nas membranas aracnoides e pia-máter, bem como, no líquido cefalorraquidiano (ZUETER; ZAITER, 2015; SILVA et al., 2017; WELLER et al., 2018; GHANNAM \& AL KHARAZI 2019). A etiologia dessa doença envolve agentes infecciosos e não infecciosos. Os agentes infecciosos predominantes são as bactérias e os vírus, com menor incidência de fungos e parasitas. Esses micro-organismos têm a capacidade de acometer as meninges causando sequelas graves e podendo levar o paciente a óbito.
Quanto aos não infecciosos, compreendem a doenças sistêmicas relacionadas às meninges, doenças autoimunes, indução por medicamentos e/ou substâncias químicas, meningites neoplásicas, dentre outros (ZUETER; ZAITER, 2015;CARDOSO et al., 2019; RAMOS et al., 2019; TATTEVIN et al., 2019). As meningites virais e bacterianas têm uma maior importância para a saúde pública se comparadas com as outras formas devido à gravidade, e sua transmissão e contágio ser rápido pelo contato próximo, de pessoa para pessoa, o que favorece ao surgimento de surtos epidêmicos. Os fatores socioeconômicos de determinadas regiões podem determinar o agente etiológico da doença, tendo como fatores agravantes a falta de higiene e saneamento básico (SILVA et al., 2020). A meningite bacteriana é uma inflamação e infecção das meninges causada por bactérias, responsável pelos casos de morbidade e mortalidade em todo o mundo. Apresenta uma evolução clínica rápida, na qual pode ocasionar sequelas irreversíveis ao paciente, como dano cerebral, perda de audição e dificuldade de aprendizado. Dentre os agentes 
etiológicos envolvidos nessa doença, a bactéria Neisseria meningitidis (meningococo), é a que acomete com maior frequência a população brasileira. Além deste micro-organismo, há uma diversidade bacteriana responsável por essa etiologia, sendo elas, Haemophilus influenzae tipo b (Hib), Streptococcus pneumoniae (pneumococo), Listeria monocytogenes, Streptococcus agalactiae, Escherichia coli, Mycobacterium tuberculosis(SILVA et al., 2017; WILKINSON et al., 2017;OORDT-SPEETSet al., 2018; CARDOSO et al., 2019; CIRILO \& LIMA, 2020). A meningite viral tem como principal agente etiológico os enterovírus não pólio, de grande relevância para a saúde pública, pelos casos de óbito ocorrido mundialmente. No entanto, com o surgimento da vacina poliovírus, os números de mortes têm diminuindo. Outros agentes etiológicos virais com potencial de mortalidade podem estar envolvidos nessa etiologia, nos quais se destacam os da família Herpesviridae (HSV-2, VZV, HSV-1) e os arbovírus (CRUZ et al., 2020). A Organização Mundial de Saúde, alerta todo o mundo para os casos de meningite, e estima que 1,2 milhões de pessoas contraem a meningite e 135 mil pessoas vão a óbito. Todas as etiologias são consideradas um grave problema para a saúde pública devida sua letalidade e propagação em massa. Como toda doença, esta quando ocasionada por micro-organismos, pode causar rápidos surtos, epidemias e até mesmo pandemias, pois sua transmissão consiste em ambientes com aglomeração de pessoas, sazonalidade, clima, fatores socioeconômicos, dentre outros (JUNIOR et al., 2020). A taxa de mortalidade da meningite varia de acordo com o diagnóstico e o tratamento precoce, que contribuem para a redução dos casos de morbimortalidade, a adesão de um tratamento empírico com base nos fatores determinantes da meningite, e consequentemente, a melhora do paciente (RAMOSet al., 2019). Dessa forma, pretendemos analisar os casos de meningites no Brasil, descrevendo o perfil epidemiológico da doença no período de 2018 a 2019 , identificando os tipos mais prevalentes de acordo com o agente etiológico, fatores relacionados ao paciente e aspectos sociais. E com isso, colaborar com as autoridades públicas e profissionais de saúde na elaboração de projetos viáveis para a contenção da doença e sua taxa de mortalidade, e desenvolver estratégias para minimizar o seu avanço tanto em âmbito hospitalar quanto comunitário.

\section{MATERIAIS E MÉTODOS}

A pesquisa desenvolvida consiste em um estudo transversal, descritivo e retrospectivo, de natureza epidemiológica e quantitativa, utilizando-se dados provenientes da base de dados do Sistema Nacional de Agravos de Notificação (SINAN), disponibilizados pelo DATASUS, no período de 2018 a 2019. Foram verificados os casos notificados positivos para meningite no Brasil, nas quais foram avaliadas as seguintes variáveis: frequência da etiologia da doença, frequência por sexo das pessoas acometidas, frequência por região de residência segundo o ano de diagnóstico, frequência pela categoria de faixa etária e grau de escolaridade das pessoas infectadas. Todos os dados epidemiológicos coletados para análise foram selecionados e obtidos por meio do aplicativo TABNET, a partir de suas caixas de opções (linha, coluna e conteúdo). Por se tratar de dados secundários de um banco de domínio público, não foi necessário submeter o trabalho ao Comitê de Ética em Pesquisa em Seres Humanos (CEP). A análise estatística foi realizada pela análise de variância Two-way Anova com o pós-teste de Bonferroni, considerando-se significativo os valores $\rho<0,05 ; \rho<0,01$ e $\rho<0,001$. Análise estatística e os gráficos foram obtidos pelo softwareGraphPad Prism ${ }^{\circledR}$ versão 5.

\section{RESULTADOS E DISCUSSÃO}

De 33.109 casos positivos de meningite no Brasil, no período de 2018 a 2019, 49,61\% $(\mathrm{n}=16.425)$ corresponde à meningite asséptica (MV), $15,23 \%(n=5.044)$ a meningite bacteriana $(M B)$ e $15,18 \%(n=5.027)$ a meningite não especificada (MNE). Dados disponíveis na Figura 1. A meningite pode ser ocasionada por diversos agentes etiológicos, na qual é denominada de acordo com o agente responsável como meningite bacteriana (Neisseria meningitidis - meningite meningocócica, Streptococcus pneumoniae - meningite pneumocócica, Mycobacterium tuberculosis - meningite tuberculosa); meningite asséptica e/ou viral; meningite criptocócica (Cryptococcus neoformans); e outras (PUTZet al., 2013; MING,HARRISON, 2017; WILKINSON et al., 2017; YOUNG, THOMAS, 2018).

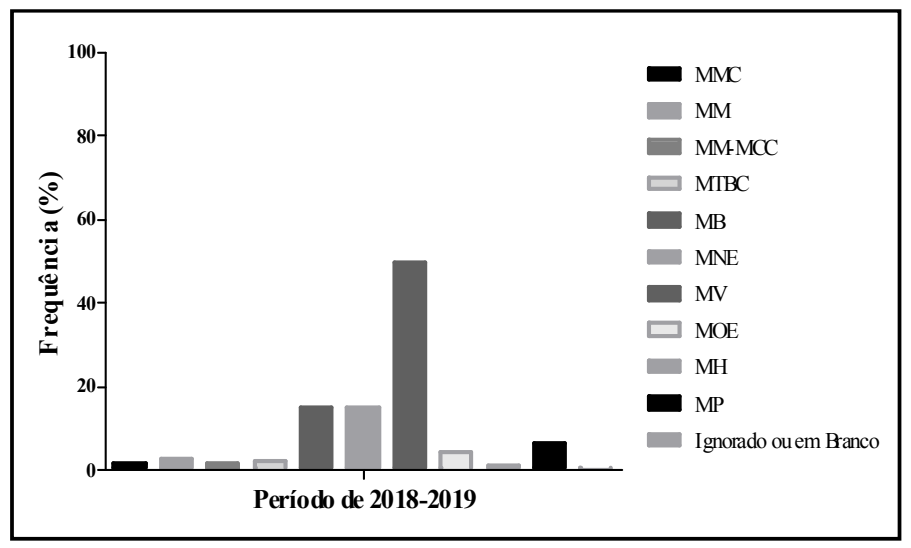

Fonte: DATASUS, 2020.

Figura 1. Casos confirmados de meningite no Brasil de acordo com a etiologia, no período de 2018-2019. MCC (Meningococemia), MM (Meningite Meningogócica), MM+ MCC (Meningite Meningocócica com Meningococemia) MTBC (Meningite Tuberculosa), MB (Meningite por outras bactérias), MNE (Meningite não especificada), MV (Meningite Asséptica), MOE (Meningite de outra etiologia), MH (Meningite por Hemófilo), MP (Meningite por Pneumococos)

A meningite asséptica é a forma mais comum, relacionada à inflamação das meninges, e não a um processo infeccioso causado por bactérias piogênicas, na qual envolve vírus e outras agentes como fármacos, doenças sistêmicas e neoplasias (PIRESet al., 2019; TATTEVIN et al., 2019; WRIGHT et al., 2019). Estudos mostram que a meningite asséptica é a mais prevalente, e que o principal agente etiológico é o vírus, destacando-se os Enterovírus e Herpesvírus humano tipo 6(DAMIANI et al., 2012; SIRIN; GOKTAS, 2018; SHIMABUKURO et al., 2019). Considerando-se a figura 2, observa-se que tanto no ano de 2018 e 2019 a meningite asséptica (MV) é a mais prevalente no Brasil, com 49,89\% ( $\mathrm{n}=8.760)$ e $49,29 \%(n=7.665)$, respectivamente, seguido dos casos notificados de MB com 15,97\% ( $n=2.804)$ em 2018 e 14,41\% $(n=2.240)$ em 2019, e MNE, com 14,47\% ( $\mathrm{n}=2.541)$ em 2018 e 15,99\% $(\mathrm{n}=2.486)$, em 2019, apresentando diferença significativa em relação aos demais tipos de meningite. Não houve diferença significativa entre o mesmo tipo de meningite em relação aos anos analisados.

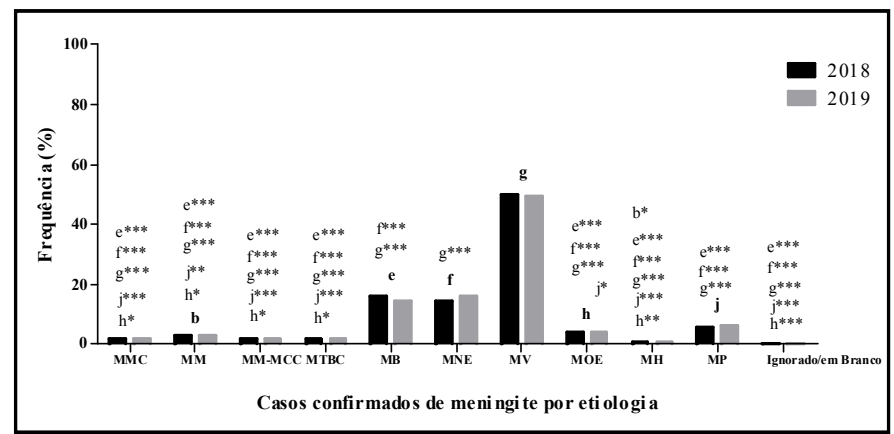

Fonte: DATASUS, 2020

MCC (Meningococemia), MM (Meningite Meningogócica), MM+ MCC (Meningite Meningocócica com Meningococemia) MTBC (Meningite Tuberculosa), MB (Meningite por outras bactérias), MNE (Meningite não especificada), MV (Meningite Asséptica), MOE (Meningite de outra etiologia), MH (Meningite por Hemófilo), MP (Meningite por Pneumococos)

Figura 2. Comparação dos casos confirmados de meningite no Brasil de acordo com a etiologia, nos anos de 2018 e 2019.

g comparado com meningite asséptica; ${ }^{\mathrm{e}}$ comparado com a meningite bacteriana; ${ }^{\mathrm{f}}$ comparado com a meningite não especificada; ${ }^{\mathrm{j}}$ comparado com a meningite pneumocócica; ${ }^{\mathrm{h}}$ comparado com a meningite de outra etiologia; ${ }^{b}$ comparado com a meningite meningocócica. * $\quad$ * $<0,05 ; \quad * * p<0,01 ; \quad * * * p<0,001$, ANOVA- 
Bonferroni. Consoante Paim e colaboradores (2019) destaca em seu estudo epidemiológico, retrospectivo, e de abordagem quantitativa, realizado nos estado de Santa Catarina, no período de 2008 a 2018, que das notificações registradas segundo a etiologia de doença a meningite viral foi a mais incidente com $41,2 \%(n=3.614$ casos), seguida pela etiologia bacteriana $29,59 \%(n=2.595$ casos $)$. Dentre as bactérias, os patógenos mais identificados foram Streptococcus pneumoniae com $4,74 \%(\mathrm{n}=416)$ casos e $N$. meningitidis com $5,81 \%$ $(\mathrm{n}=510$ casos). A meningite causada por Haemophilus influenzae correspondeu a apenas $0,54 \%(n=47$ casos $)$. Dezoito por cento dos casos 1.582 casos foram ocasionados por outras bactérias. De acordo com Oliveira e colaboradores (2019), em seu estudo retrospectivo e descritivo, realizado no estado do Paraná, no período de 2010 a 2018, registrou a notificação de 624 casos de meningite. Dentre os municípios analisados, Curitiba apresentou o maior número de caso, com $29,9 \%$ da doença meningocócica, $24 \%$ da forma clínica Meningite Meningogócica, $38.5 \%$ de Meningite Meningogócica e $37.4 \%$ de Meningite Meningocócica com Meningococemia. A pesquisa de Magalhães e Santos (2018) alerta para os principais patógenos causadores de meningites bacterianas, por acometer pessoas em unidades hospitalares, sendo fundamental que as unidades de saúde estejam aptas para identificá-los precocemente, com adesão a modernas técnicas laboratoriais. Dentre esses patógenos tem-se: Neisseria meningitidis, Streptococcus pneumoniae, Haemophilus influenzae sorotipo b (Hib) e Streptococcus agalactiae. É importante ressaltar que de acordo com a Portaria GM n ${ }^{\circ} 3$ de 21 de fevereiro de 2006 do Ministério da Saúde, a meningite tornou-se uma doença de notificação compulsória, pela maior capacidade de causar surtos epidêmicos, bem como, pelo elevado grau de mortalidade, evidenciando um grave problema para a Saúde Pública.

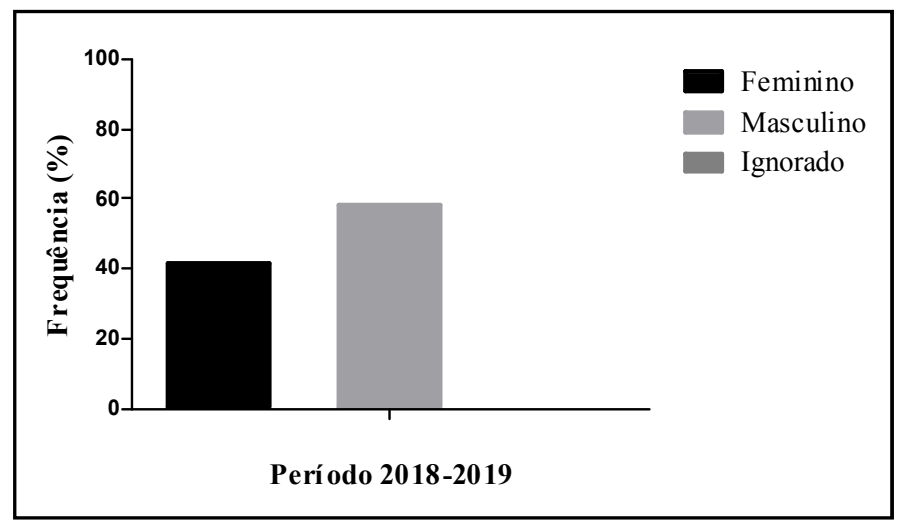

Fonte: DATASUS, 2020.

Figura 3. Casos confirmados de meningite no Brasil de acordo com a variável do sexo, no período de 2018-2019

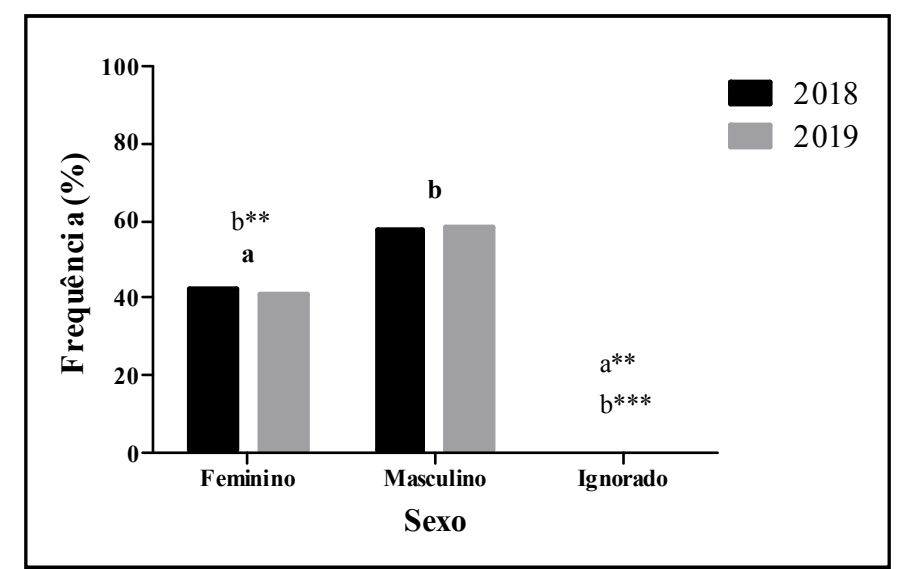

Fonte: DATASUS, 2020.

b comparado com o sexo masculino; ${ }^{a}$ comparado com o sexo feminino. $* p<0,05 ; * * p<0,01 ; * * * p<0,001$, ANOVA-Bonferroni.

Figura 4. Comparação dos casos confirmados de meningite no Brasil de acordo com a variável do sexo, nos anos de 2018 e 2019
A meningite viral ocasiona a maioria dos casos de surtos epidêmicos, enquanto a meningite bacteriana causa maior taxa de mortalidade da população (JUNIOR et al., 2020). A pesquisa mostrou que os homens são os mais acometidos pela meningite do que as mulheres. Dentre uma população de 33.121 casos positivos de meningite, $58,20 \%$ $(n=19.277)$ corresponde ao sexo masculino e $41,79 \%(n=13.840)$, ao sexo feminino (Figura 3). No entanto, quando se compara os períodos, não foi observado diferença significativa, em que o sexo masculino em 2018, apresentou 52,63\% ( $\mathrm{n}=10.145)$, e o feminino, $53,62 \%$ $(n=7.421)$; e em 2019, o sexo masculino correspondeu a $47,37 \%$ $(n=9.132)$ e feminino, 46,38\% $(n=6.419)$. Dados mostrados na figura 4. O estudo de Fontes (2019) sobre os casos confirmados de meningites no estado do Piaú, no período de 2007 a 2017, concorda com os dados desta pesquisa, no qual evidenciou que o sexo masculino foi o mais acometido com $61,10 \%(n=2.184)$ e o sexo feminino apresentou 38,90\% $(\mathrm{n}=1.391)$. Contudo, Gonçalves e Mezzaroba (2018), em seu estudo de delineamento ecológico, dos casos notificados de meningite no Brasil, em 2015, demonstra que o sexo feminino foi o mais atingido pela doença, com $60 \%(n=5.515)$ dos casos confirmados. De acordo com a Organização Mundial da Saúde (OMS), o sexo masculino é mais suscetível a desenvolver qualquer tipo de problema de saúde, pois está em constante atividade física em contato com o mundo externo, o que aumenta as chances de contágio por enteroviroses. Muitos são os fatores que a população masculina tem para desenvolver a meningite, os homens são relutantes em buscar ajuda médica, procura tardia por atenção primária, não adesão ao tratamento de comorbidades crônicas que pode agravar o quadro da meningite, e consequentemente, ocasionar a óbito (SILVA GOMES et al., 2019). Na figura 5, observa-se que as populações entre 20-39 anos e 1-4 anos foram as mais acometidas pela meningite, respectivamente, com $19,59 \%(n=6.487)$ e $18,84 \%$ (6.241). Seguida das faixas etárias menor que 1 ano $(16,02 \%, \mathrm{n}=5.304), 40-59$ anos $(14,75 \%, \mathrm{n}=4.884)$ e $5-9$ anos $(11,96 \%, \mathrm{n}=3.962)$.

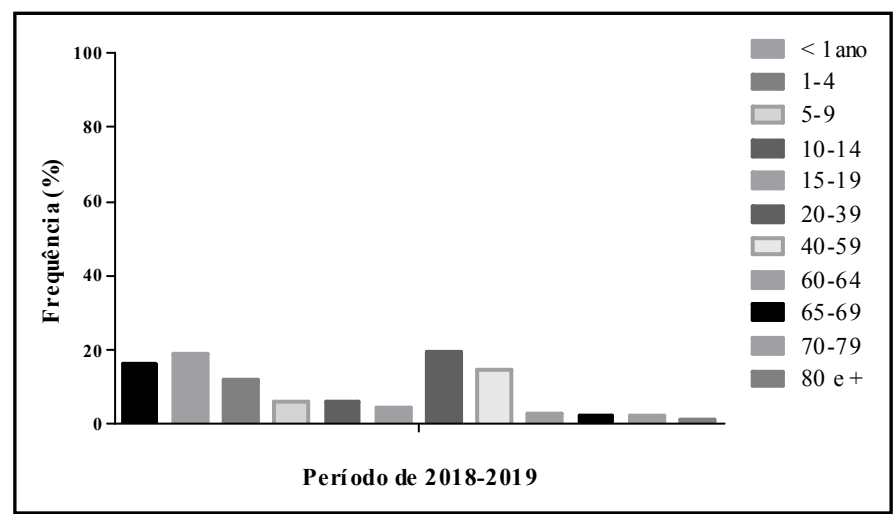

Fonte: DATASUS, 2020.

Figura 5. Casos confirmados de meningite no Brasil, de acordo com a variável faixa etária da população, no período de 2018-2019

Quando se compara os casos positivos de meningite considerando-se a faixa etária em relação aos anos de 2018 e 2019, observa-se que a faixa etária predominante foi de 20-39 anos, correspondendo a $19,52 \% \quad(n=3.429)$, em 2018, e 19,67\% (n=3.058), em 2019. Entretanto, não se verifica diferença significativa entre o mesmo tipo de meningite e faixa etária, porém é significante entre os diferentes tipos de meningite e faixas etárias (Figura 6). ${ }^{\mathrm{f}}$ comparado com a faixa etária entre 20-39 anos; ${ }^{b}$ comparado com a faixa etária entre 1-4 anos; ${ }^{a}$ comparado com a faixa etária $<1 \mathrm{ano} ;{ }^{\mathrm{g}}$ comparado com a faixa etária entre 40-59 anos; ${ }^{\mathrm{c}}$ comparado com a faixa etária entre 5-9 anos; ${ }^{\mathrm{d}}$ comparado com a faixa etária entre 10-14 anos; ${ }^{\mathrm{e}}$ comparado com a faixa etária entre $15-19$ anos; ${ }^{\mathrm{h}}$ comparado com a faixa etária entre 60-64 anos; O estudo de Gouvêa (2018), em sua pesquisa descritiva e epidemiológica, sobre a meningite no Brasil, no período de 2014 a 2017, destaca a faixa etária mais acometida pela doença, sendo ela em crianças menores de cinco anos, com 3,0 casos a cada 10 mil habitantes no ano de 2015, e em 2016 com 2,1 casos de Meningite a cada 100 mil habitantes. 


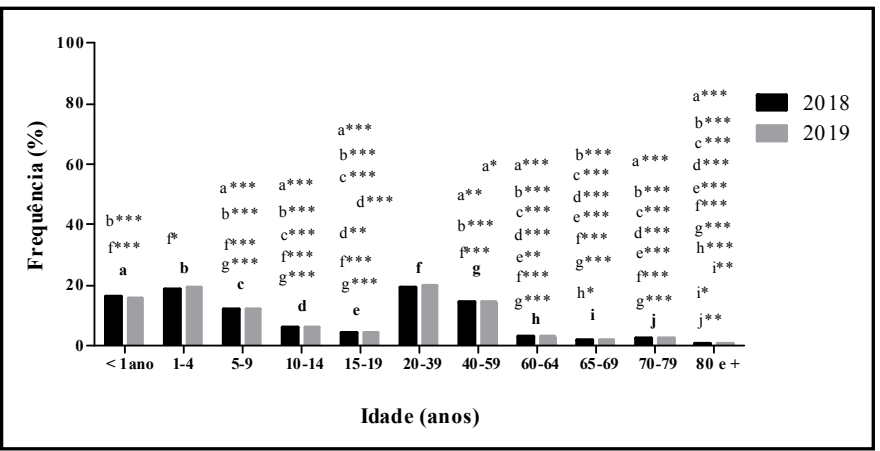

Fonte: DATASUS, 2020.

${ }^{\mathrm{f}}$ comparado com a faixa etária entre $20-39$ anos; ${ }^{\mathrm{b}}$ comparado com a faixa etária entre 1-4 anos; ${ }^{\mathrm{a}}$ comparado com a faixa etária $<1 \mathrm{ano} ;{ }^{\mathrm{g}}$ comparado com a faixa etária entre $40-59$ anos; ${ }^{\mathrm{c}}$ comparado com a faixa etária entre $5-9$ anos; ${ }^{\mathrm{d}}$ comparado com a faixa etária entre 10-14 anos; ${ }^{\mathrm{e}}$ comparado com a faixa etária entre 15-19 anos; ${ }^{\mathrm{h}}$ comparado com a faixa etária entre 60-64 anos; comparado com a faixa etária entre $65-69$ anos; ${ }^{\mathrm{j}}$ comparado com a faixa etária entre 70-79 anos. $* p<0,05 ; * * p<0,01 ; * * * p<0,001$, ANOVA-Bonferroni.

Figura 6. Comparação dos casos confirmados de meningite no Brasil, de acordo com a variável faixa etária da população, nos anos de 2018 e 2019

É comum que crianças e adolescentes sejam os mais acometidos pela meningite, pois o sistema imunológico ainda é imaturo, o que resulta numa resposta imune sem eficácia, essa faixa etária também está diretamente ligada à ocupação de espaços com aglomerações (FONTES, 2019). A gravidade da meningite vai estar diretamente associada à faixa etária do paciente, prontidão do seu sistema imunológico, agente etiológico causador da meningite, comorbidades, diagnóstico e tratamento antecipado da doença, por isso os recémnascidos e lactantes tem maior incidência de mortalidade, pois seu sistema imune não tem habilidade de elaborar uma resposta eficaz contra micro-organismos invasores (ZANIN et al., 2020). Crepaldi e colaboradores (2018), em seu estudo estatístico, analítico e retrospectivo, realizado no Hospital de São Luiz Gonzaga, estado de São Paulo, no período de janeiro de 1998 a julho de 2010, relatou que dos 161 casos analisados, a média de idade foi de 32,7 anos. E de acordo com a faixa etária, $51,6 \%$ dos casos equivale a idade entre 10 29 anos; $31,1 \%$ a $30-49$ anos; $13 \%$ a $50-69$ anos; e $4,3 \%$ a $70-89$ anos. É importante evidenciar quanto a variável faixa etária, que a imunidade adquirida na infância pelo processo de imunização por vacinas, perde seu efeito de proteção, o que torna as pessoas adultas mais suscetíveis a uma infecção por meningite, o que corrobora com esta pesquisa, em que a faixa etária mais acometida foi a de 20-39 anos. Outro fator considerável para os elevados casos de meningite são movimentos antivacinas. Os indivíduos adultos são mais resistentes em se imunizar, pois os mesmo não distinguem a diferença entre ciência e idiossincrasias (JUNIOR et al., 2020). Considerando os casos de positivos de meningite quanto à zona de residência, no período de 2018 a 2019 (Figura 7), a maior prevalência foi na zona urbana (92,15\%, n=30.521). Comparando-se os dados de 2018 e 2019, observa-se que não há diferença significativa entre os casos de meningite e as mesmas zonas de residência. Contudo, entre as diferentes zonas de residência, há diferença significativa (Figura 8).

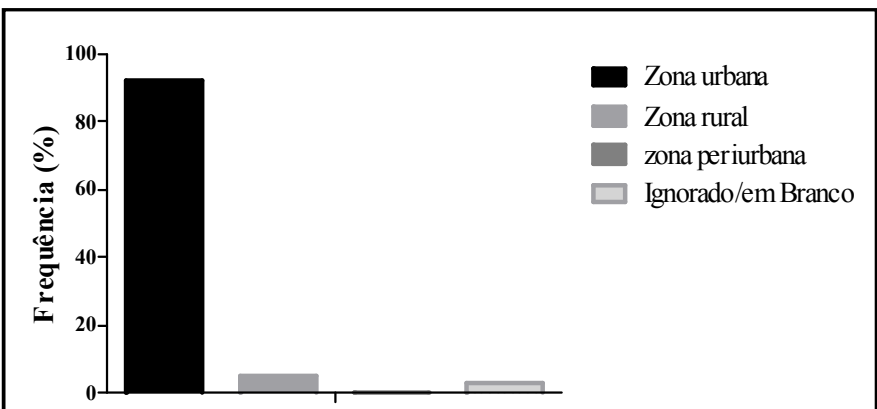

Período de 2018-2019

Fonte: DATASUS, 2020

Figura 7. Casos confirmados de meningite no Brasil, de acordo com a variável zona de residência da população, no período de 2018-2019

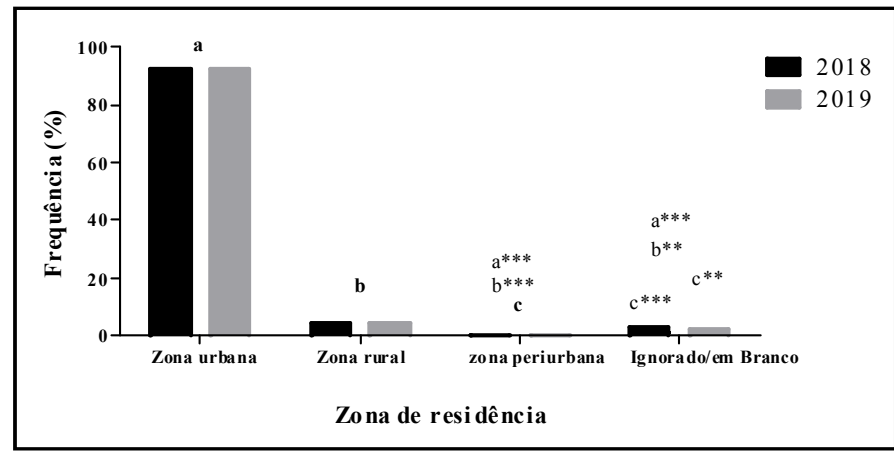

Fonte: DATASUS, 2020.

a comparado com zona urbana; ${ }^{\mathrm{b}}$ comparado com a zona rural; ${ }^{\mathrm{c}}$ comparado com a zona periurbana. * $p<0,05 ; * * p<0,01 ; * * * p<0,001$, ANOVABonferroni.

Figura 8. Comparação dos casos confirmados de meningite no Brasil, de acordo com a variável zona de residência da população, nos anos de 2018 e 2019.

Estudos mostram dados semelhantes à pesquisa realizada, em que a zona urbana é a mais afetada pela meningite. Oliveira e colaboradores (2019), em sua pesquisa, descritiva e retrospectiva, no Estado de Goiás, no período de 2015 a 2017, constatou que a zona urbana foi a mais acometida pela meningite, apresentando 96,47\% dos casos, correspondente às cidades de Goiânia e Rio Verde. Maçaneiro (2018), em seu estudo epidemiológico no Estado de Santa Catarina, munícipio de Tijucas-SC, no período de janeiro de 2007 a dezembro de 2017, também observou que a prevalência de casos ocorre na zona de residência urbana. Na zona urbana o índice de disseminação por meningites virais ou bacterianas são mais elevadas, pois é nesta área geográfica que há maior concentração de pessoas, que vivem em sociedade e contato diretamente, tendo como principais vias de transmissão àsgotículas de saliva, espirro e beijo (MATOS et al., 2020). Na tabela 1 observam-se os casos de meningite de acordo com a variável, grau de escolaridade da população, em que as populações do ensino médio completo, da $5^{\mathrm{a}}$ a $8^{\mathrm{a}}$ série incompleta e $1^{\mathrm{a}}$ a $4^{\mathrm{a}}$ série incompleta foram as mais acometidas, em ambos os anos analisados, com um total de 6,8\% $(n=2.252), 5,93 \%(n=1.965)$ e 4,55\% (1.506), respectivamente. É importante ressaltar que 29,18\% dos casos ou foram ignorados ou não registrados. Sabe-se que os casos de meningite devem ser obrigatoriamente notificados. Dessa forma, informações relevantes são subnotificadas.

Tabela 1. Frequência dos casos confirmados de meningite no Brasil, de acordo com a variável grau de instrução da população, no período de 2018-2019

\begin{tabular}{lccc}
\hline Grau de escolaridade & $2018[\%(\mathrm{n})]$ & $2019[\%(\mathrm{n})]$ & Total \\
\hline Ignorado ou em branco & $30,21(5.307)$ & $28,02(4.357)$ & 9.664 \\
$\begin{array}{l}\text { Analfabeto } \\
1^{\mathrm{a}} \text { a } 4^{\mathrm{a}} \text { série incompleta do }\end{array}$ & $\begin{array}{c}0,45(79) \\
\text { ensino fundamental }\end{array}$ & $0,48(75)$ & 154 \\
$\begin{array}{l}4^{\mathrm{a}} \text { série completa do ensino } \\
\text { fundamental }\end{array}$ & $2,00(351)$ & $1,64(254)$ & 605 \\
$\begin{array}{l}5^{\mathrm{a}} \text { a } 8^{\mathrm{a}} \text { série incompleta do } \\
\text { ensino fundamental }\end{array}$ & $5,78(1.016)$ & $6,10(949)$ & 1.965 \\
$\begin{array}{l}\text { Ensino fundamental } \\
\text { completo }\end{array}$ & $3,33(585)$ & $3,03(471)$ & 1.056 \\
$\begin{array}{l}\text { Ensino médio incompleto } \\
\text { Ensino médio completo }\end{array}$ & $2,73(480)$ & $3,12(486)$ & 966 \\
$\begin{array}{l}\text { Educação superior } \\
\text { incompleto }\end{array}$ & $1,08(1.113)$ & $7,32(1.139)$ & 2.252 \\
$\begin{array}{l}\text { Educação superior } \\
\text { completa }\end{array}$ & $2,59(455)$ & $1,18(183)$ & 373 \\
$\begin{array}{l}\text { Não se aplica } \\
\text { Total }\end{array}$ & $41,11(7.221)$ & $41,64(6.475)$ & 13.696 \\
\hline Fonte: DATASUS, 2020. & $100(17.566)$ & $100(15.551)$ & 33.117 \\
\hline
\end{tabular}

De acordo com Amorim e colaboradores (2017), em seu estudo observacional epidemiológico, descritivo, realizado no Estado de Minas Gerais, no período de 2007 a 2015, observou que dos 656 casos analisados, $62 \%$ eram do sexo masculino e tinham escolaridade 
inferior ao ensino médio completo. Entretanto, segundo Barata e colaboradores (2020), o grau de instrução não é muito relevante para as ocorrências da meningite, o que concorda com esta pesquisa, em que podemos verificar na tabela 1 , que indivíduos analfabetos não foram tão acometidos, representando até minoria quando comparados a outros graus de instruções. No entanto, Junior Macedo (2020) menciona que a precariedade da educação coloca as pessoas em risco, pois a orientação e prevenção são meios fundamentais para reduzir as altas taxas de mortalidade. A educação melhora a qualidade de vida das pessoas, uma vez que o indivíduo munido do saber está mais preparado para se proteger e como proceder em caso de contrair a doença.

\section{CONCLUSÃO}

A meningite continua sendo um grave problema para a saúde pública, apresentando alta taxa de mortalidade. Em que a meningite asséptica é a mais prevalente, e acomete principalmente indivíduos do sexo masculino, adultos e crianças entre 1 a 4 anos, residentesna zona urbana, com ensino fundamental completo e incompleto. É importante ressaltar que o diagnóstico tardio da meningite contribui para o elevado número de óbitos. É evidente que a vacina é o método mais eficaz em longo prazo para combater a elevada taxa de mortalidade causada pela meningite. Assim, é relevante desenvolver ações e campanhas para adesão as vacinas disponibilizadas pelo Ministério da Saúde. Dessa forma, alertamos as autoridades de saúde pública, para que medidas e programas sejam criados para almejar uma possível erradicação da doença, implantar em unidades de saúde laboratórios para que seja possível diagnosticar precocemente a presença de agentes patógenos causadores de meningite, e capacitar os profissionais de saúde quanto aos sintomas clínicosproporcionando o diagnóstico por observação. É importante que a notificação compulsória seja feita corretamente, para que os casos de meningite não sejam subnotificados, e com isso, a vigilância epidemiológica possa ter um maior controle nas estatísticas. E que ações possam ser estabelecidas sobre os valores reais dos casos de meningite, melhorando o manejo clínico do paciente e ações de educação em saúde para lidar com a prevenção. Em suma, melhorar a qualidade de vida da população e reduzir a letalidade e morbidade.

\section{REFERENCIAS}

Alves MM. (2018). Meningites bacterianas. Revista Enfermagem e Saúde Coletiva-REVESC, 2(1).

Barata RS. Vieira CM, Oliveira RAC, Guedes JA, Gonçalves NV. (2020). A meningite criptocócica: analise espacial, epidemiologia e fatores de risco no estado do pará, amazônia oriental brasileira. Hygeia-Revista Brasileira de Geografia Médica e da Saúde, 16, 74-83.

Cardoso LDCC, Santos MKA, Mariano NF. (2019, September). Caracterização do perfil epidemiológico de meningite: estudo ecológico na Região Nordeste de 2008 a 2018. In Congresso Internacional de Enfermagem (Vol. 1, No. 1).

Cirilo T, Lima, JAPA. (2020). Incidência de meningite meningocócica no estado do paraná em crianças menores de 14 anos. Revista Experiências e Evidências em Fisioterapia e Saúde-ISSN 2595-7872, 1(1), 13-21.

Crepaldi PIS, Dias CAR, Lariucci R, Silva RMV, Gianella JCB, Sanvito WL, Lebre, AT. (2018). Estudo epidemiológico e clínico sobre meningite em adultos no setor de emergência em São Paulo/Epidemiologicalstudyandclinicreport of meningitis in adults in the sector of emergency in São Paulo. Arquivos Médicos dos Hospitais e da Faculdade de Ciências Médicas da Santa Casa de São Paulo, 59(1), 1-6.

Cruz JVNS, Santos Nascimento M, Aragão Oliveira TAM, Nunes IRS, Souza LG, Souza Andrade Filho A. (2020). Perfil epidemiológico das meningites virais no estado da bahia entre 2007 E 2018. Revista Brasileira de Neurologia e Psiquiatria, 24(1).
Damiani D, Furlan MC, Damiani D. (2012). Meningite asséptica. RevBrasClin Med. São Paulo, 10(1), 46-50.

Ghannam JY, Al Kharazi KA. Neuroanatomia, meninges cranianas. 2019.

Gonçalves HC, Mezzaroba N. (2018). Meningite no Brasil em 2015: o panorama da atualidade. Arquivos Catarinenses de Medicina, 47(1), 34-46.

Gouvêa MDC. (2018). Caracterização epidemiológica e diagnóstico da doença Meningocócica no Brasil, 2014-2017.

JUNIOR AMDM. (2020). Perfil epidemiológico e fatores determinantes na saúde ambiental da tuberculose no brasil. Revista Ibero-Americana de Ciências Ambientais, 11(7).

Junior JDDT, Quaresma MP, Teixeira RAV, Pinto LC. (2020). Retrato da epidemiologia da meningite no Estado do Pará entre 2015 e 2018. BrazilianJournal of Health Review, 3(4), 1075510770.

Júnior RDSS. PERFIL DOS CASOS DE NEUROCISTICERCOSE OCORRIDOS NO BRASIL: ANÁLISE DE ESTUDOS DOS ÚLTIMOS 15 ANOS. Realização, 66.

Lima Fontes FL. (2019). Aspectos epidemiológicos da meningite no estado do Piauí: 2007 a 2017. Revista Ciência \& SaberesUniFacema, 4(4).

Lima Oliveira D, Silveira MB, Gomes JG, Casanova C, Manrique EJC. (2019). Doença meningocócica: perfil clínicoepidemiológico e laboratorial no estado de goiás. Ciência \& Desenvolvimento-Revista Eletrônica da FAINOR, 12(3).

Maçaneiro PHC. Levantamento epidemiológico de doenças infectocontagiosas e seus vetores no município de Tijucas-SC. 2018.

Magalhães RS, Santos MS. (2018). Perfil epidemiológico da meningite bacteriana no Município de Vitória da ConquistaBahia, no período de 2008 a 2015. Revista de Ciências Médicas e Biológicas, 17(1), 33-39.

Matos AC, Fecury AA, Oliveira E, Dendasck, CV, Dias CAGM. Número de casos confirmados de meningite no Brasil no período de 2011 a 2015. Revista Científica Multidisciplinar Núcleo do Conhecimento, 5(5), 121-130, 2020.

Nascimento ANC, Araújo MS, Morais VMO, Pinheiro MS. (2019, September). Quadro de hospitalizações por meningite viral e bacteriana durante a infância e adolescência na última década: um estudo epidemiológico. In Congresso Internacional de Enfermagem (Vol. 1, No. 1).

Oliveira, AA, Zechim, ACC, COSTA KMD, OLIVEIRA-LIMA RSMD. (2019). situação epidemiológica da doença meningocócica, nos municípios do noroeste do estado do paraná, Brasil.

Oordt-speets AM, Bolijn R, Hoorn RC, Bhavsar a, Kyaw MH. Global etiology of bacterial meningitis: A systematic review and metaanalysis. PlosOne, 13(6), 1-16, 2018.

Paim ACB, Gregio MM, Garcia SP (2019). Perfil epidemiológico da meningite no estado de santa catarina no período de 2008 a 2018. Arquivos Catarinenses de Medicina, 48(4), 111-125.

Pires SAP, Lemos AP, Pereira EPMN, Maia PADSV, Agro JPDS. (2019). Meningite asséptica induzida por ibuprofeno: um caso clínico. Revista Paulista de Pediatria, 37(3), 382-385.

Ramos CG, Sá BA, Freitas LFM, Moura JA, Lopes MVBV, Gonçalves E. (2019). Meningites bacterianas: epidemiologia dos casos notificados em minas gerais entre os anos de 2007 e 2017. Revista Eletrônica Acervo Saúde, (22), e655-e655.

Shimabukuro SN, Fernandes LS, Neto JZ, Nakahara KR, Cavalli LO. (2019). Situação epidemiológica da meningite em município da região sul do brasil com foco na etiologia mais comum. fag journal of health (FJH), 1(4), 38-43.

Silva ACB, Conceição Rodrigues EL, Trindade EL. (2020). Avaliação dos casos de meningite por definição do agente etiológico no estado do pará entre os anos de 2010 a 2019. BrazilianJournal of Health Review, 3(4), 7729-7736.

Silva Gomes L, Silva Passos BV, Silva Azevedo PS, Júnior FTDSS, Sampaio LS, Matos LFL, Verde RMCL. (2019). Aspectos epidemiológicos das meningites virais no estado do Piauí no período de 2007 a 2017. Revista Eletrônica Acervo Saúde, 11(10), e433-e433. 
Sirin MC, Goktas S. (2018). Determination of theprevalence of viral, bacterialandfungalpathogenscau-singmeningitisbyusing multiplex real-time polymerasechainreaction. Acta MedMedit, 34, 127-132.

Tattevin P, Tchamgoué, S., Belem A, Bénézit, F, Pronier C, Revest M. (2019). Asepticmeningitis. Revueneurologique, 175(7-8), 475-480.

Weller RO, Sharp MM, Christodoulides M, Carare R. O, Møllgård $\mathrm{K}$. As meninges como barreiras e facilitadoras para a movimentação de fluidos, células e patógenos relacionados ao SNC humano e de roedores. Acta neuropathologica, 135(3), 363$385,2018$.
Wilkinson RJ, Rohlwink U, Misra UK, Crevel R, Mai NTH, Kelly E, Dooley, Caws M, Figaji A, Savic R, Solomons R, Thwaites GE. Tuberculous meningitis.NatureReviewsNeurology, 13 (10), 581-598.

WRIGHT, W. F.; PINTO, C. N.; PALISOC, K.; BAGHLI, S. 2019. Viral (aseptic) meningitis: A review. Journal of theNeurologicalSciences, v. 398, p. 176-183.

Zanin EB, Czapla BL, Fukuyama ACW, Ortinã TTC, Silva Lima UT. (2020). Perfil epidemiológico das meningites em pacientes pediátricos na cidade de cascavel/pr em 10 anos. Revista Thêmaet Scientia, 10(1E), 120-130.

Zueter AM, Zaiter A. Infectiousmeningitis. Clinical Microbiology Newsletter, v. 37, n. 6, p. 43-50, 2015. 